Check for updates

Cite this: RSC Adv., 2019, 9, 4862

Received 29th November 2018 Accepted 27th January 2019

DOI: $10.1039 / c 8 r a 09812 c$

rsc.li/rsc-advances

\section{A simple liquid chromatography-tandem mass spectrometry method to accurately determine the novel third-generation EGFR-TKI naquotinib with its applicability to metabolic stability assessment}

\author{
Haitham Alrabiah, ${ }^{a}$ Adnan A. Kadi, ${ }^{a}$ Mohamed W. Attwa (D) *ab \\ and Ali S. Abdelhameed (D)
}

Naquotinib (ASP8273, NQT) is a novel third-generation epidermal growth factor receptor tyrosine kinase inhibitor (EGFR-TKIs). NQT was found to be more effective than osimertinib against the EGFR L858R plus T790M mutation (L858R+T790M). A rapid resolution liquid chromatography (RRLC)-tandem mass spectrometry (MS/MS) method was developed and validated for NQT quantification and its metabolic stability was investigated. NQT and foretinib (FTB) as an internal standard (IS) were separated using a mobile phase under isocratic conditions with a C18 column (reversed phase system). The linearity of the analytical method ranged from 5 to $500 \mathrm{ng} \mathrm{mL}^{-1}$ (coefficient of correlation $\left[r^{2}\right] \geq 0.9999$ ) in a human liver microsome (HLM) matrix. The limit of detection and limit of quantification were 0.78 and $2.36 \mathrm{ng} \mathrm{mL}^{-1}$, respectively. The inter-day and intra-day accuracy and precision were -6.36 to 1.88 and 0.99 to $2.58 \%$, respectively. The metabolic stability of NQT in the HLM matrix was calculated using the in vitro half-life $\left(t_{1 / 2}, 67.96 \mathrm{~min}\right)$ and intrinsic clearance $\left(\mathrm{Cl}_{\text {int }}, 2.12 \mathrm{~mL} \mathrm{\textrm {min } ^ { - 1 }}\right.$ $\mathrm{kg}^{-1}$ ). NQT is considered to be a moderate extraction ratio drug that is moderately excreted from the human body compared with other related TKIs. This proposed methodology is thought to be the first method for assessing NQT concentration and its metabolic stability.

\section{Introduction}

Non-small cell lung cancer (NSCLC) is a common and widespread subgroup of lung cancers ${ }^{1-5}$ and it has an incidence of $90 \%$ of all patients suffering from lung cancer. The epidermal growth factor receptor (EGFR) signaling pathway attained considerable importance a few years ago as a therapeutic target in NSCLC. ${ }^{6}$ Tyrosine kinase inhibitors (TKIs) that control the EGFR are very efficacious in EGFR mutation treatment with a characteristic therapeutic window. First-line TKIs controlling EGFR (e.g. erlotinib and gefitinib) are characterized by an initially good response against these mutations. ${ }^{7,8}$ Unfortunately, acquired resistance in approximately $60 \%$ of patients and the toxicities associated with treatment ${ }^{9,10}$ have decreased their therapeutic efficacies. ${ }^{\mathbf{1 1 , 1 2}}$ This encouraged scientists to develop second-generation irreversible EGFR TKIs (e.g., dacomitinib and avitinib). ${ }^{13,14}$ However, NSCLC was shown to acquire resistance to first- and second-generation EGFR-TKIs in approximately 1 year. ${ }^{15}$ The EGFR T790M mutation is found in approximately $50 \%$ of NSCLCs resistant to first- and second-

${ }^{a}$ Department of Pharmaceutical Chemistry, College of Pharmacy, King Saud University, P. O. Box 2457 Riyadh, 11451, Kingdom of Saudi Arabia. E-mail: halrabiah@ksu.edu. sa; akadi@ksu.edu.sa; mzeidan@ksu.edu.sa; asaber@ksu.edu.sa; Fax: +966114676 220; Tel: +966114670237

${ }^{b}$ Students' University Hospital, Mansoura University, Mansoura 35516, Egypt generation EGFR-TKIs. The second-generation EGFR TKIs (e.g. dacomitinib and avitinib) address the drawbacks of first-line TKIs in the first year from the beginning of treatment. ${ }^{\mathbf{8} 13}$

The third-generation TKIs maintain the second-generation drugs' benefits by preventing EGFR mutations and surmounting the T790M resistance mutation. ${ }^{\mathbf{1 3 , 1 4}}$ Naquotinib (ASP8273, NQT) is considered a novel third-generation EGFRTKI and was found to be more effective than osimertinib against the L858R plus T790M mutation (L858R+T790M). Additionally, naquotinib and osimertinib showed a wide therapeutic window and similar efficacy for EGFR exon 20 insertions cells. ${ }^{16}$

A review of the literature proved there were no published chromatographic methods for NQT assay; therefore, we were prompted to establish an LC-MS/MS methodology for this target. The estimation of bioavailability provides an idea of the compound metabolism. If the test drug is quickly metabolized, it will show a low in vivo bioavailability value. ${ }^{17}$ NQT could be considered a moderate extraction ratio drug and, hence, is moderately excreted from the human body compared to other TKIs. ${ }^{18-21}$ This implies a lower risk of drug accumulation inside the body in comparison to other TKIs (e.g. dacomitinib). Therefore, the metabolic stability of NQT was determined by computing two important parameters (intrinsic clearance and in vitro half-life $\left[t_{1 / 2}\right]$ ) that could be utilized to further calculate 
other physiological parameters (e.g., in vivo $t_{1 / 2}$, bioavailability and hepatic clearance).

\section{Experimental}

\subsection{Reagents and chemicals}

Naquotinib (99.12\%) and foretinib (99.81\%) were procured from MedChemExpress (USA). Acetonitrile (ACN, HPLC grade), formic acid $(\mathrm{HCOOH})$, ammonium formate $\left(\mathrm{NH}_{4} \mathrm{COOH}\right)$ and human liver microsomes, pooled (HLMs, M0567) were procured from Sigma-Aldrich (USA). HPLC grade water $\left(\mathrm{H}_{2} \mathrm{O}\right)$ was prepared by a filtration system (Milli-Q Plus, USA).

\subsection{LC-MS/MS methodology}

All LC-MS/MS parameters were optimized to attain the best chromatographic separation of NQT and FTB (IS) with high resolution (Table 1). FTB was selected as the IS in the NQT analysis because the same extraction method could be utilized for both substances (NQT and FTB recoveries were 98.61 \pm $2.42 \%$ and $98.7 \pm 0.7 \%$, respectively, in the HLM matrix) and the elution time of FTB is comparable to that of NQT. The supposed method is fast with a short run time (4 min). Both FTB and NQT are TKIs and were not co-administered to patients, so this method could be utilized for clinical applications, such as pharmacokinetics or therapeutic drug monitoring (TDM), for patients under naquotinib treatment.

A triple quadrupole (QqQ) mass spectrometer with an electrospray ionization source interface (ESI, positive mode) was

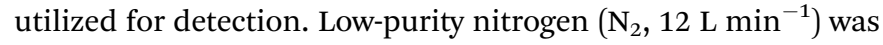
utilized as the drying gas in the ESI source while high-purity $\mathrm{N}_{2}$ (55 psi) was used as the collision gas. The ESI temperature (T) and capillary voltage $(\mathrm{V})$ were set at $350{ }^{\circ} \mathrm{C}$ and $3500 \mathrm{~V}$, respectively. The instruments and data acquisition were controlled using Mass Hunter software. NQT was quantified using the

A)

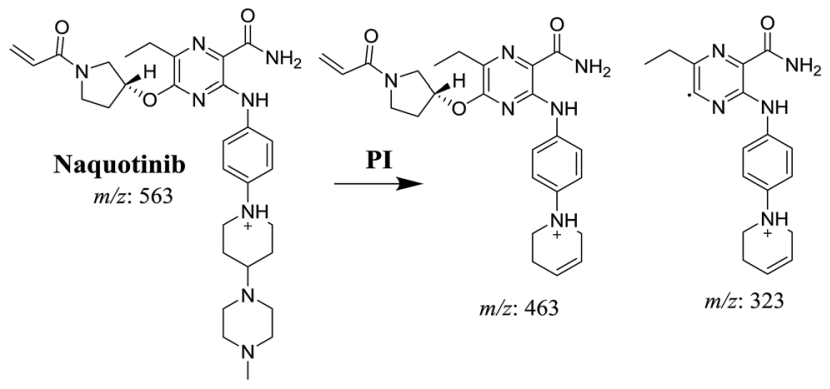

B)

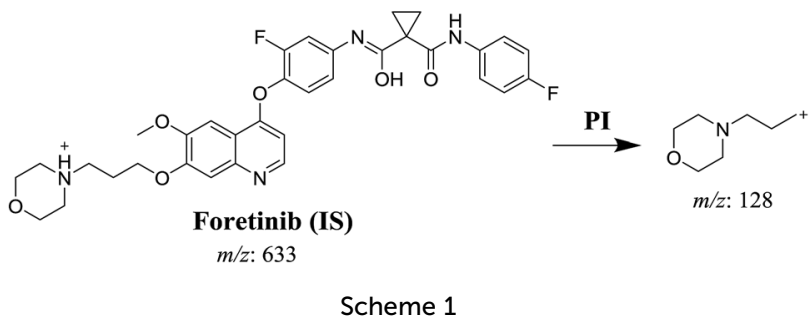




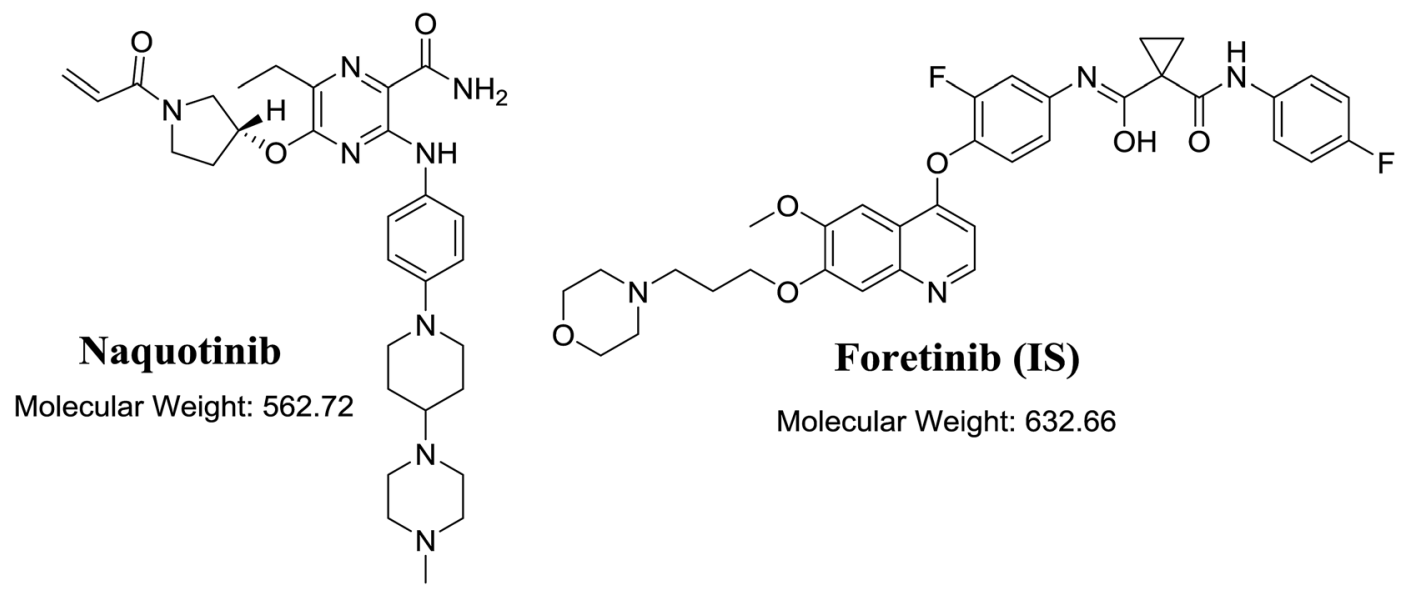

Fig. 1 Chemical structure of naquotinib and foretinib (internal standard [IS]).

analyzer mode of multiple reaction monitoring (MRM) for the mass reactions (parent to fragment ions) from $563 \rightarrow 463$ and $563 \rightarrow 323$ for NQT and $633 \rightarrow 128$ for FTB (Scheme 1). The fragmentor voltage (FV) was adjusted to 125 and $130 \mathrm{~V}$ with collision energies (CEs) of 22 and 18 for NQT, and an FV of $145 \mathrm{~V}$ with CE of 20 for FTB. The MRM mass analyzer mode was utilized for NQT quantification to erase any interference of the HLM constituents and to elevate the sensitivity of the proposed LC-MS/MS method (Fig. 1 and 2).

\subsection{NQT calibration stock solutions}

Both NQT and FTB are soluble in dimethyl sulfoxide (DMSO). NQT ( $2 \mathrm{mg} \mathrm{mL}^{-1}$ in DMSO) was diluted 10 -fold in the mobile phase to make working NQT solution 1 (WK1, $200 \mu \mathrm{g} \mathrm{mL} \mathrm{m}^{-1}$ ), which was further diluted to prepare WK2 $\left(20 \mu \mathrm{g} \mathrm{mL}{ }^{-1}\right)$. FTB $\left(100 \mu \mathrm{g} \mathrm{mL}^{-1}\right.$ in DMSO) was diluted 50-fold in the mobile phase to make WK3 $\left(1 \mu \mathrm{g} \mathrm{mL} \mathrm{mL}^{-1}\right)$.

\subsection{Preparation of NQT calibration standards}

WK2 was mixed with a specific HLM matrix $(40.00 \mu \mathrm{L}$ in $1 \mathrm{~mL}$ of phosphate buffer) to establish a calibration curve of 12 standards: $5.00,10.00,15.00,30.00,50.00,80.00,100.00,150.00$, $200.00,300.00,400.00$, and $500.00 \mathrm{ng} \mathrm{mL}^{-1}$. Four concentration levels, $5,15,150$, and $400 \mathrm{ng} \mathrm{mL}^{-1}$, were selected as the lower limit quality control (LLQC), low quality control (LQC), medium quality control (MQC), and high quality control (HQC), respectively. NQT and FTB were extracted using an acetonitrile (ACN) protein precipitation method for the metabolic stability experiments. ${ }^{22}$ ACN $(2 \mathrm{~mL})$ was added to each milliliter of the standard solution, followed by centrifugation (14000 rpm for 12 min) in a thermostatic centrifuge at $4{ }^{\circ} \mathrm{C}$ to precipitate proteins and refine the sample to remove unwanted materials. Then, $1 \mathrm{~mL}$ of each supernatant was collected and filtered using a syringe filter $(0.22 \mu \mathrm{m}$ pore size). WK3 $(50 \mu \mathrm{L})$ was added, followed by transference of the mixtures to $1.5 \mathrm{~mL}$ vials. The injection volume was $1 \mu \mathrm{L}$ to facilitate the adjustment of the peak shape by enhancing the sharpness. Control samples were similarly prepared as described above, using the stated phosphate buffer without the HLM matrix to verify that the components of HLM did not interfere at NQT and FTB retention times. A standard calibration curve was constructed by plotting the peak area ratio of NQT to FTB ( $y$-axis) against NQT nominal
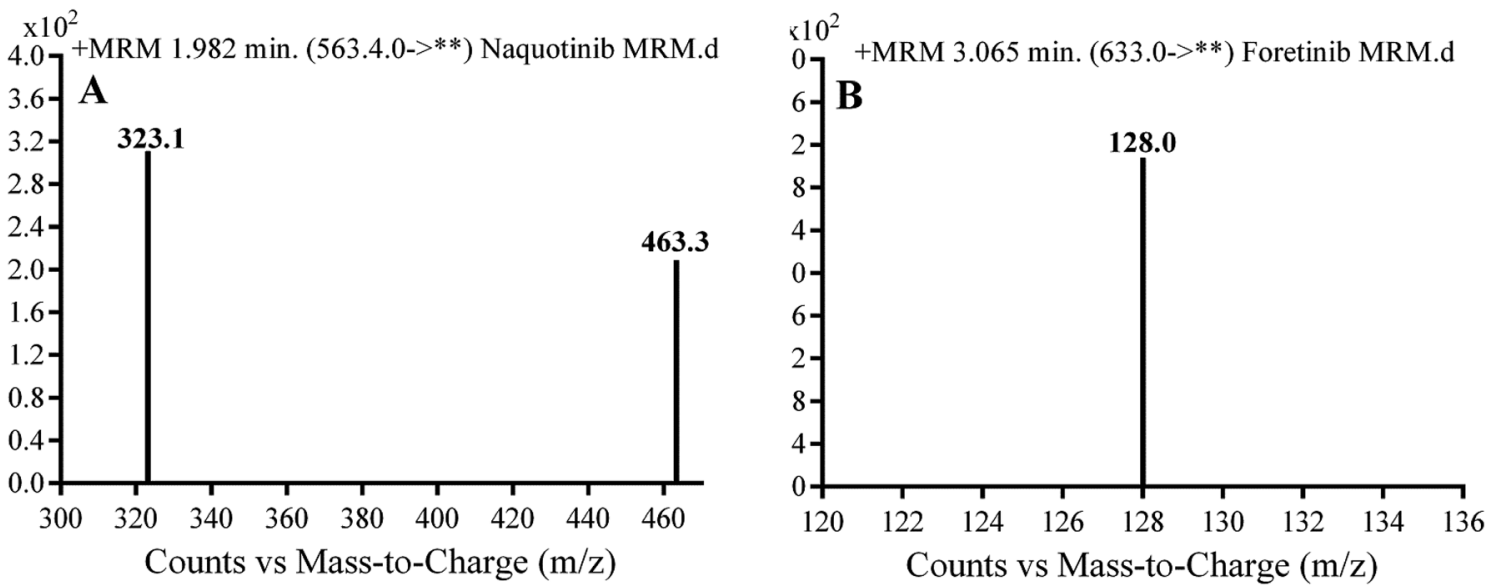

Fig. 2 Multiple reaction mode (MRM) mass spectral transitions of (A) naquotinib (NQT) and (B) foretinib (IS). 


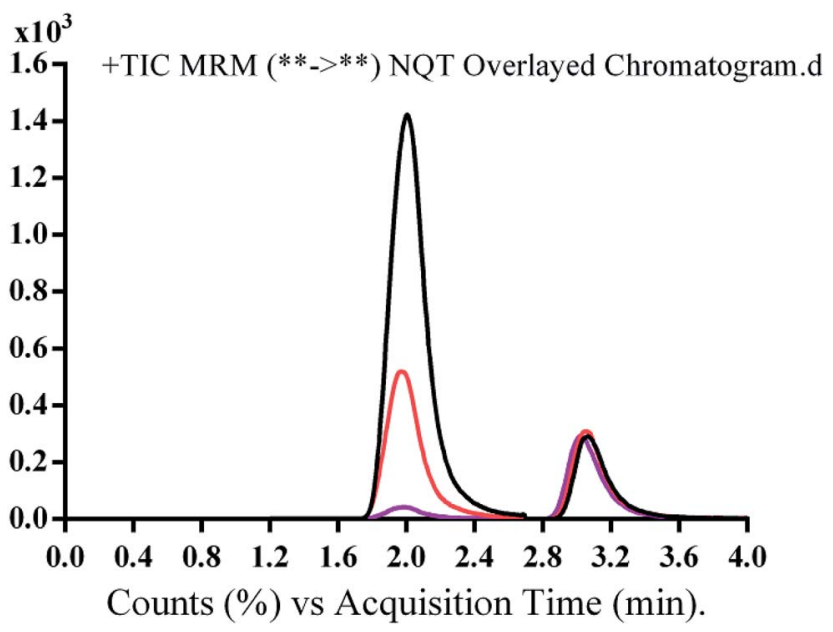

Fig. 3 Overlayed multiple reaction mode (MRM) chromatograms of quality control (QC) standards of naquotinib (NQT, 15, 150, and $400 \mathrm{ng}$ $\mathrm{mL}^{-1}$ ) and FTB (50 $\left.\mathrm{ng} \mathrm{mL}^{-1}\right)$.

values ( $x$-axis). A linear regression equation was utilized to verify the linearity of the supposed method. The slope, intercept, and coefficient of correlation $\left(r^{2}\right)$ values were computed.

\subsection{Method validation}

Parameters for validation of the supposed LC-MS/MS method for NQT assay were described in detail in our previous articles. $^{21-23}$ The following validation parameters, linearity, assay recovery, sensitivity, reproducibility, specificity, limit of quantification (LOQ), and limit of detection (LOD), were utilized for the computation. All validation parameters were computed for NQT. The least squares statistical method was utilized for statistical calculation of the calibration curve equations $(y=a x$ $+b)$. A linear fit was verified by the $r^{2}$, which showed linearity in the range of 5-500 $\mathrm{ng} \mathrm{mL} \mathrm{mL}^{-1}$. The recovery of NQT in the spiked HLM matrix was $98.61 \pm 2.42 \%$ (relative standard deviation $[\mathrm{RSD}]<2.68 \%)$.

\subsection{Metabolic stability of NQT}

The NQT metabolic stability was determined by assessing the NQT concentration remaining after incubation with HLMs. Briefly, $1 \mu \mathrm{M}$ of NQT was incubated with HLMs $(1 \mathrm{mg}$ microsomal protein per $1 \mathrm{~mL}$ phosphate buffer) and the experiment was repeated three times for confirmation of the results. The metabolic reaction was performed in phosphate buffer ( $\mathrm{pH} 7.4)$ containing magnesium chloride $\left(\mathrm{MgCl}_{2}, 3.3 \mathrm{mM}\right)$. The mixture was pre-incubated for $10 \mathrm{~min}$ in a thermostated water bath (37 $\left.{ }^{\circ} \mathrm{C}\right)$ and then the metabolic reactions were initiated and subsequently stopped by adding NADPH ( $1 \mathrm{mM})$ and $2 \mathrm{~mL} \mathrm{ACN}$, respectively, at specific time intervals: $0,2.5,5,7.5,10,15,20$, 40,50 , and $70 \mathrm{~min}$. The metabolic stability curve for NQT was subsequently constructed.

\section{Results and discussion}

\subsection{HPLC-MS/MS methodology}

Chromatographic conditions, including mobile phase $\mathrm{pH}$ and composition, and the stationary phase, were optimized. The $\mathrm{pH}$ of the aqueous part (10 $\mathrm{mM}$ ammonium formate) was adjusted to 4.2 using formic acid because at a higher $\mathrm{pH}$, peak tailing and an excessive increase in retention time were observed. The ratio between the aqueous and organic parts (ACN) was set to $55: 45 \%$, because an increase in the ACN ratio resulted in overlapping chromatographic peaks with bad peak resolution, whereas a decrease in the ratio increased the elution time. Various types of stationary phases such as HILIC columns were tested, but NQT and FTB were not retained and good results were finally attained using a C18 column. MRM was used for NQT quantification to remove any HLM matrix interference and enhance the sensitivity of the proposed LC-MS/MS method (Fig. 2).

The run time for complete elution of NQT and FTB was 4 min with good resolution. There was no carryover in the blank HLM matrix sample. Fig. 3 shows the NQT QC standards as overlaid MRM chromatograms.
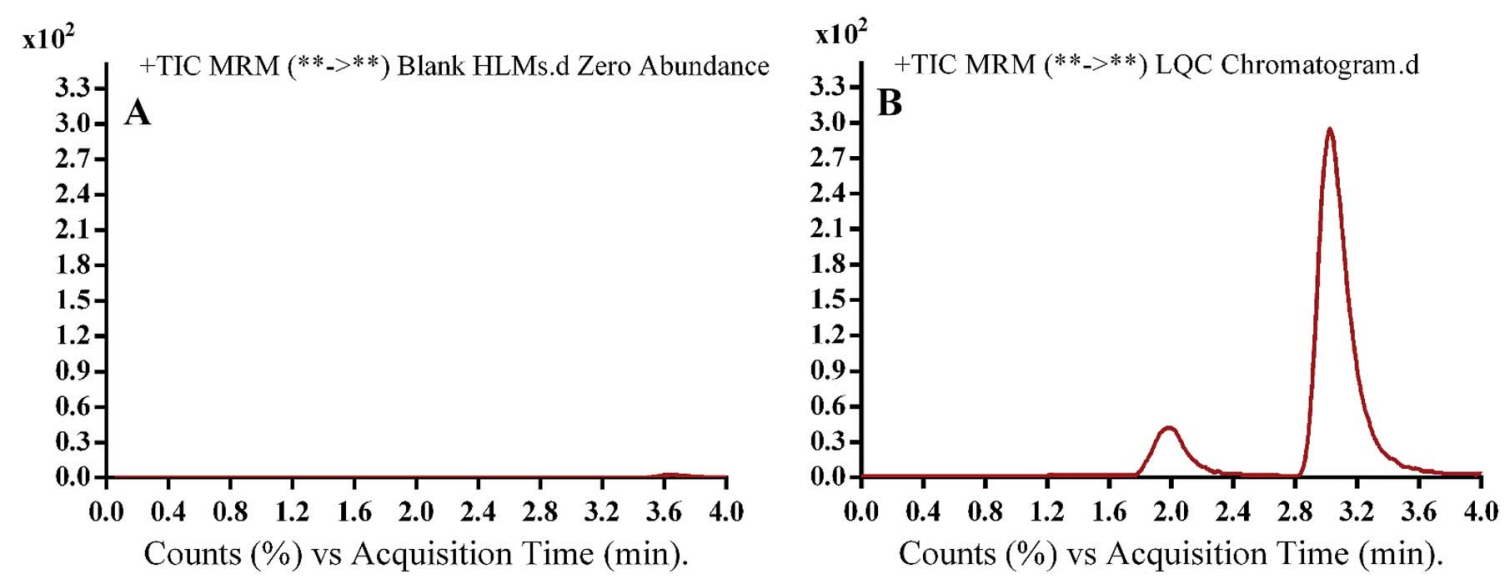

Fig. 4 Multiple reaction monitoring (MRM) chromatograms of (A) blank human liver microsomes (HLMs) and (B) naquotinib (NQT, 15 ng mL ${ }^{-1}$, low quality control [LQC]). Blank HLM matrix revealed no matrix interference. 


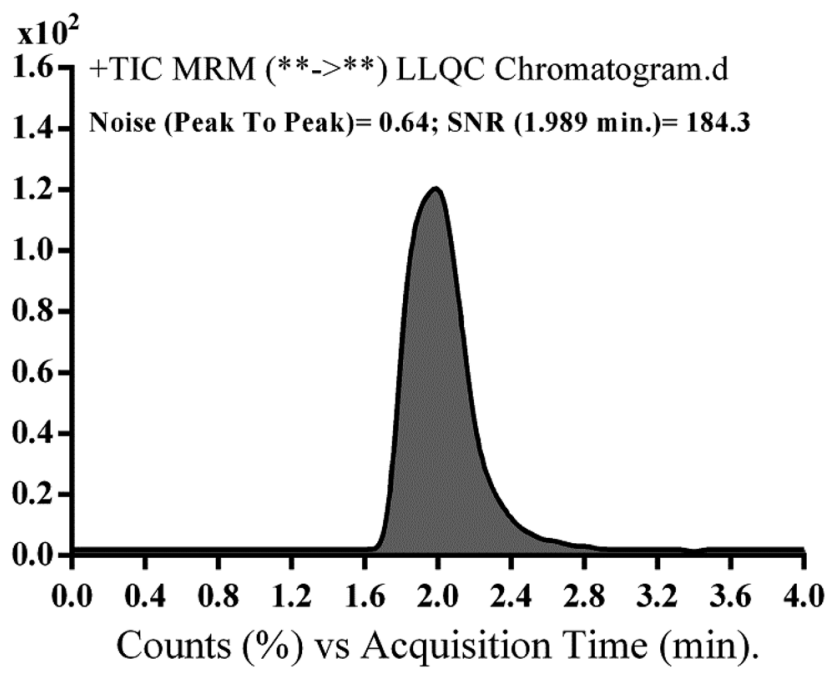

Fig. 5 Naquotinib lower limit quality control (LLQC) multiple reaction monitoring (MRM) chromatogram revealed high signal to noise $(S / N)$ ratio.

Table 2 Naquotinib (NQT) back-calculated calibration standard concentrations from human liver microsome (HLM) matrix

\begin{tabular}{lrrrr}
\hline $\begin{array}{l}\text { NQT Nominal concentrations } \\
\left(\mathrm{ng} \mathrm{mL}^{-1}\right)\end{array}$ & Mean $^{a}$ & SD & RSD (\%) & $\begin{array}{l}\text { Accuracy } \\
(\%)\end{array}$ \\
\hline 5 (LLQC) & 5.28 & 0.08 & 1.52 & -5.65 \\
10 & 10.29 & 0.21 & 2.07 & -2.95 \\
15 (LQC) & 14.85 & 0.23 & 1.52 & 1.00 \\
30 & 28.66 & 0.60 & 2.10 & 4.46 \\
50 & 50.18 & 0.76 & 1.51 & -0.36 \\
80 & 78.07 & 2.09 & 2.68 & 2.42 \\
100 & 100.94 & 1.75 & 1.74 & -0.94 \\
150 (MQC) & 148.18 & 2.49 & 1.68 & 1.21 \\
200 & 201.63 & 2.28 & 1.13 & -0.82 \\
300 & 294.62 & 2.20 & 0.75 & 1.79 \\
400 (HQC) & 397.32 & 2.76 & 0.70 & 0.67 \\
500 & 496.02 & 5.79 & 1.17 & 0.80
\end{tabular}

${ }^{a}$ Mean of six replicates; RSD, relative standard deviation.

\subsection{Validation of the LC-MS/MS method}

3.2.1. Specificity. Fig. 4 shows good separation of the NQT and FTB peaks and the lack of any peak in the blank HLM matrix at their retention times, which proved the specificity of the established method. No carryover effect of NQT or FTB was seen in the MRM chromatograms.

3.2.2. Sensitivity and linearity. The range of linearity and $r^{2}$ for the supposed method were $5-500 \mathrm{ng} \mathrm{mL} \mathrm{mL}^{-1}$ and $\geq 0.9999$, respectively, in the HLM matrix. The regression equation of the NQT calibration curve was $y=1.5581 x-3.395$. The LOD and LOQ were 0.78 and $2.36 \mathrm{ng} \mathrm{mL^{-1 }}$, respectively, while the LLQC peak showed a high signal to noise $(\mathrm{S} / \mathrm{N})$ ratio and a good peak shape, suggesting the sensitivity of the developed LC-MS/MS method (Fig. 5).

The RSD values of the six repetitions of each calibration level were $<1.96 \%$ in the HLM matrix (Table 2). Back calculations for the 12 NQT standards in the HLM matrix (calibration and QC standards) confirmed the performance of the established method. The intra-day and inter-day precisions and accuracies were 0.99 to $2.58 \%$ and -6.36 to 1.88 , respectively (Table 3 ). The average NQT recoveries were $98.61 \pm 2.42 \%$ in the HLM matrix (Fig. 6).

3.2.3. Precision and accuracy. As can be seen in Table 3, the values of the intra- and inter-day accuracy and precision are acceptable according to FDA guidelines. ${ }^{24}$

3.2.4. Matrix effects and extraction recovery. Table 4 shows the percentage recovery of the QC samples for computing the NQT level in the HLM matrix. The NQT and FTB recoveries were $98.61 \pm 2.42$ and $98.7 \pm 0.7 \%$ in the HLM matrix, respectively. The absence of a matrix effect on NQT or FTB was proven by analyzing two batches of HLMs, which were spiked with NQT LQC and FTB (15 and $50 \mathrm{ng} \mathrm{mL}^{-1}$, respectively). These batches were marked as set 1 . Set 2 was prepared using the mobile phase in place of the HLM matrix and, thus, the matrix effect was calculated using the following equation:

$$
\begin{aligned}
& \text { matrix effect of NQT }=\text { mean peak area ratio } \frac{\text { set } 1}{\text { set } 2} \times 100 \\
& \text { matrix effect of } \mathrm{FTB}=\text { mean peak area ratio } \frac{\text { set } 1}{\text { set } 2} \times 100
\end{aligned}
$$

The studied HLMs containing NQT and FTB showed matrix effects of $98.61 \pm 2.42$ and $98.7 \pm 0.7 \%$, respectively. The internal standard normalized matrix effect (IS normalized MF) was computed using the following equation:

\begin{tabular}{|c|c|c|c|c|c|c|c|c|}
\hline \multirow[b]{2}{*}{ HLM matrix } & \multicolumn{2}{|c|}{ LLQC $\left(5 \mathrm{ng} \mathrm{mL}^{-1}\right)$} & \multicolumn{2}{|c|}{ LQC (15 $\left.\mathrm{ng} \mathrm{mL}^{-1}\right)$} & \multicolumn{2}{|c|}{ MQC (150 ng mL $\left.{ }^{-1}\right)$} & \multicolumn{2}{|c|}{$\mathrm{HQC}\left(400 \mathrm{ng} \mathrm{mL} \mathrm{L}^{-1}\right)$} \\
\hline & Intra-day assay $^{b}$ & Inter-day assay $^{c}$ & $\begin{array}{l}\text { Intra-day } \\
\text { assay }\end{array}$ & $\begin{array}{l}\text { Inter-day } \\
\text { assay }\end{array}$ & $\begin{array}{l}\text { Intra-day } \\
\text { assay }\end{array}$ & $\begin{array}{l}\text { Inter-day } \\
\text { assay }\end{array}$ & $\begin{array}{l}\text { Intra-day } \\
\text { assay }\end{array}$ & $\begin{array}{l}\text { Inter-day } \\
\text { assay }\end{array}$ \\
\hline Mean & 5.28 & 5.32 & 14.85 & 14.75 & 148.18 & 147.18 & 397.32 & 393.32 \\
\hline SD & 0.08 & 0.05 & 0.23 & 0.38 & 2.49 & 2.71 & 2.76 & 6.70 \\
\hline Precision (\%RSD) & 1.52 & 0.99 & 1.52 & 2.58 & 1.68 & 1.84 & 0.70 & 1.70 \\
\hline
\end{tabular}

Table 3 Intra-day and inter-day (accuracy and precision) of established method $^{a}$

${ }^{a}$ HLM, human liver microsome; LLQC, lower limit quality control; LQC, low quality control; MQC, medium quality control; HQC, high quality control. ${ }^{b}$ Mean of twelve replicates on the same day. ${ }^{c}$ Mean of six replicates for three days. 


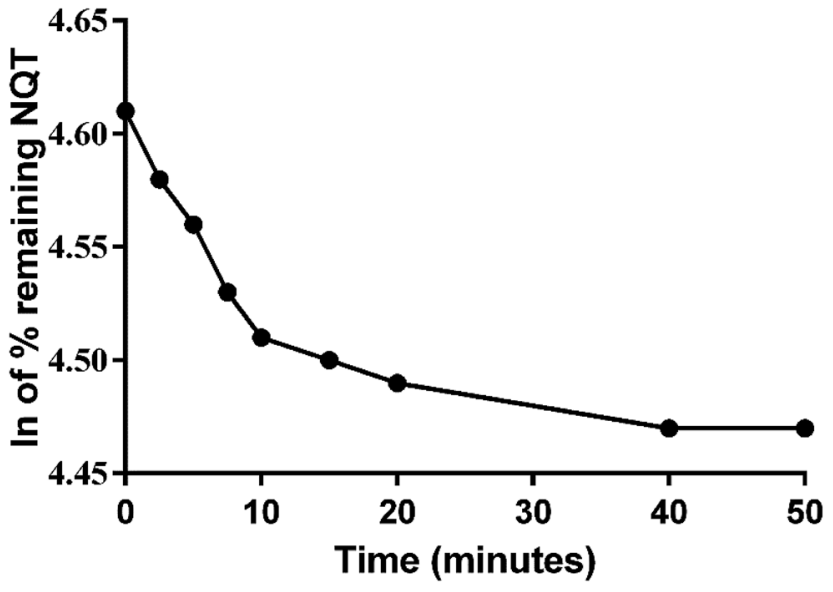

Fig. 6 Metabolic stability curve of naquotinib (NQT) in human liver microsomes (HLMs).

Table 4 Recovery of naquotinib (NQT) samples in human liver microsome (HLM) matrix

\begin{tabular}{|c|c|c|c|c|}
\hline \multirow[b]{2}{*}{ Conc. (ng $\left.\mathrm{mL}^{-1}\right)$} & \multicolumn{4}{|c|}{ HLM matrix } \\
\hline & $5 \mathrm{ng} \mathrm{mL}^{-1}$ & $15 \mathrm{ng} \mathrm{mL}^{-1}$ & $\begin{array}{l}150 \\
\mathrm{ng} \mathrm{mL}^{-1}\end{array}$ & $400 \mathrm{ng} \mathrm{mL}^{-1}$ \\
\hline $\operatorname{Mean}^{a}$ & 5.09 & 14.85 & 143.89 & 391.34 \\
\hline SD & 0.05 & 0.38 & 2.56 & 5.40 \\
\hline Precision $\left(\mathrm{RSD}^{\circ}{ }^{b}\right)$ & 0.99 & 2.58 & 1.78 & 1.38 \\
\hline Recovery (\%) & 101.71 & 98.98 & 95.93 & 97.83 \\
\hline FTB recovery & \multicolumn{4}{|c|}{$98.7 \pm 0.7 \%$} \\
\hline
\end{tabular}

${ }^{a}$ Mean of six replicates. ${ }^{b}$ RSD, relative standard deviation.

$$
\text { IS normalized MF }=\frac{\text { matrix effect of OTB }}{\text { matrix effect of PNT (IS) }}
$$

The IS normalized MF was 1.01 and it was within the range of adequacy. ${ }^{25}$ Accordingly, these results showed that the HLM matrix had no obvious influence on the ionization of NQT or FTB.

\subsection{Metabolic stability}

The NQT concentration in the HLM matrix was calculated by displacing the peak area ratios in the calibration curve regression equation. The metabolic stability curve was constructed by plotting the ln NQT percentage remaining on the $y$-axis against the time of incubation on the $x$-axis (Fig. 5). The linear part of the regression equation was used for computing in vitro $t_{1 / 2}{ }^{26}$ The regression equation was $y=-0.0102 x+4.6069$ with $r^{2}=$ 0.9981 (Table 5).

Using the following equations:

$$
\text { In vitro } t_{1 / 2}=\frac{\ln 2}{\text { slope }}
$$

the slope was calculated to be 0.0044 .

$$
\text { In vitro } t_{1 / 2}=\frac{\ln 2}{0.0102}
$$

$$
\text { In vitro } t_{1 / 2}=67.96 \mathrm{~min}
$$

The intrinsic clearance of NQT was computed using the in vitro $t_{1 / 2}$ method $^{17}$ using the following equation:

$$
\begin{aligned}
\mathrm{Cl}_{\text {int }, \text { app }}= & \frac{0.693}{\text { in vitro } t_{1 / 2}} \times \frac{\mathrm{mL} \text { incubation }}{\mathrm{mg} \text { microsomes }} \times \frac{45 \mathrm{mg} \text { microsome }}{\mathrm{g} \text { liver }} \\
& \times \frac{20 \mathrm{~g} \text { liver }}{\mathrm{kg} \text { per body weight }}
\end{aligned}
$$

\begin{tabular}{|c|c|c|c|c|}
\hline 0 & 446.22 & 4.61 & Regression equation $^{b}$ & $y=-0.0102 x+4.6069$ \\
\hline 5.00 & 424.60 & 4.56 & $r^{2 c}$ & 0.9981 \\
\hline 7.50 & 413.26 & 4.53 & & \\
\hline 10.00 & 403.56 & 4.51 & Slope & 0.0102 \\
\hline 40.00 & 391.25 & 4.47 & & \\
\hline 50.00 & 390.14 & 4.47 & $\mathrm{Cl}_{\text {int }}^{e}$ & $2.12 \mathrm{~mL} \mathrm{~min}{ }^{-1} \mathrm{~kg}^{-1}$ \\
\hline 90.00 & 387.01 & 4.46 & & \\
\hline
\end{tabular}

$$
\mathrm{Cl}_{\text {int, app }}=\frac{0.693}{67.96} \times \frac{1}{1} \times \frac{45}{13.1} \times \frac{20}{0.331}
$$

$$
\mathrm{Cl}_{\text {int, app }}=2.12 \mathrm{~mL} \mathrm{~min}^{-1} \mathrm{~kg}^{-1}
$$

Table 5 Metabolic stability parameters of naquotinib (NQT) incubated with human liver microsomes (HLMs) for specific time intervals

NQT metabolic stability parameters

${ }^{a} X:$ ln of percentage of NQT remaining. ${ }^{b}$ Linear part regression equation. ${ }^{c}$ Correlation coefficient. ${ }^{d}$ Half-life.$~{ }^{e}$ Intrinsic clearance. 
These results revealed that the metabolic stability of NQT was characterized by a very low $\mathrm{Cl}_{\text {int }}\left(2.12 \mathrm{~mL} \mathrm{~min}{ }^{-1} \mathrm{~kg}^{-1}\right)$ and very long in vitro $t_{1 / 2}$ value $(67.96 \mathrm{~min})$ that revealed the moderate clearance of NQT from the blood by the liver and possible well-controlled in vivo bioavailability. This drug could be utilized without accumulation inside the body or fast elimination from the blood. ${ }^{27}$

\section{Conclusions}

An LC-MS/MS method was established and validated for quantifying NQT. The established method exhibited good sensitivity, was eco-friendly with the small volume of ACN used, fast, accurate, and showed high recovery. The LC-MS/MS method was utilized for NQT metabolic stability assessment in an HLM matrix using two parameters: in vitro $t_{1 / 2}$ and $\mathrm{Cl}_{\text {int }}$. These two outcomes indicate that NQT showed moderate clearance from the blood by the liver and possible well-controlled in vivo bioavailability. ${ }^{28-30}$ Therefore, this drug could be utilized without concerns about accumulation inside the body or fast elimination from the blood.

\section{Conflicts of interest}

The authors declare no conflict of interest.

\section{Abbreviations}

$\begin{array}{ll}\text { CE } & \text { Collision energy } \\ \text { EGFR } & \text { Epidermal growth factor receptor } \\ \text { FV } & \text { Fragmentor voltage } \\ \text { HLMs } & \text { Human liver microsomes } \\ \text { HQC } & \text { High quality control } \\ \text { IS } & \text { Internal standard } \\ \text { IS normalized } & \text { Internal standard normalized matrix effect } \\ \text { MF } & \\ \text { LC-MS/MS } & \text { Liquid chromatography tandem mass } \\ & \text { spectrometry } \\ \text { LOD } & \text { Limit of detection } \\ \text { LQC } & \text { Lower quality control } \\ \text { LOQ } & \text { Limit of quantification } \\ \text { MQC } & \text { Medium quality control } \\ \text { NSCLC } & \text { Non-small cell lung cancer } \\ \text { NQT } & \text { Naquotinib } \\ \text { FTB } & \text { Foretinib } \\ \text { QC } & \text { Quality control } \\ \text { TKI } & \text { Tyrosine kinase inhibitor } \\ \text { RRLC } & \text { Rapid resolution liquid chromatography }\end{array}$

\section{Acknowledgements}

The authors would like to extend their sincere appreciation to the Deanship of Scientific Research at the King Saud University for funding this work through the Research Group Project No. RG-1435-025.

\section{References}

1 R. L. Siegel, K. D. Miller and A. Jemal, CA Cancer J. Clin., 2016, 66, 7-30.

2 S. M. Haghgoo, A. Allameh, E. Mortaz, J. Garssen, G. Folkerts, P. J. Barnes and I. M. Adcock, Eur. J. Pharmacol., 2015, 754, 82-91.

3 I. Abubakar, T. Tillmann and A. Banerjee, Lancet, 2015, 385, 117-171.

4 D. S. Ettinger, W. Akerley, G. Bepler, M. G. Blum, A. Chang, R. T. Cheney, L. R. Chirieac, T. A. D'Amico, T. L. Demmy and A. K. P. Ganti, J. Natl. Compr. Cancer Network, 2010, 8, 740-801.

5 J. E. Larsen, T. Cascone, D. E. Gerber, J. V. Heymach and J. D. Minna, Cancer J., 2011, 17, 512.

6 D. B. Costa and S. S. Kobayashi, Transl. Lung Cancer Res., 2015, 4, 809.

7 C. Gridelli, A. Rossi, D. P. Carbone, J. Guarize, N. Karachaliou, T. Mok, F. Petrella, L. Spaggiari and R. Rosell, Nat. Rev. Dis. Primers, 2015, 1, 15009.

8 S. Peters, S. Zimmermann and A. A. Adjei, Cancer Treat. Rev., 2014, 40, 917-926.

9 G. Metro and L. Crinò, Transl. Lung Cancer Res., 2012, 1, 5.

10 M. G. Denis, A. Vallée and S. Théoleyre, Clin. Chim. Acta, 2015, 444, 81-85.

11 S. Jorge, S. Kobayashi and D. Costa, Braz. J. Med. Biol. Res., 2014, 47, 929-939.

12 M. R. V. Finlay, M. Anderton, S. Ashton, P. Ballard, P. A. Bethel, M. R. Box, R. H. Bradbury, S. J. Brown, S. Butterworth, A. Campbell, C. Chorley, N. Colclough, D. A. E. Cross, G. S. Currie, M. Grist, L. Hassall, G. B. Hill, D. James, M. James, P. Kemmitt, T. Klinowska, G. Lamont, S. G. Lamont, N. Martin, H. L. McFarland, M. J. Mellor, J. P. Orme, D. Perkins, P. Perkins, G. Richmond, P. Smith, R. A. Ward, M. J. Waring, D. Whittaker, S. Wells and G. L. Wrigley, J. Med. Chem., 2014, 57, 8249-8267.

13 C.-S. Tan, D. Gilligan and S. Pacey, Lancet Oncol., 2015, 16, e447-e459.

14 B.-C. Liao, C.-C. Lin and J. C.-H. Yang, Curr. Opin. Oncol., 2015, 27, 94-101.

15 D. R. Camidge, W. Pao and L. V. Sequist, Nat. Rev. Clin. Oncol., 2014, 11, 473.

16 T. Hirano, H. Yasuda, J. Hamamoto, S. Nukaga, K. Masuzawa, I. Kawada, K. Naoki, T. Niimi, S. Mimasu, H. Sakagami, K. Soejima and T. Betsuyaku, Mol. Cancer Ther., 2018, 17, 740-750.

17 P. Baranczewski, A. Stanczak, K. Sundberg, R. Svensson, A. Wallin, J. Jansson, P. Garberg and H. Postlind, Pharmacol. Rep., 2006, 58, 453-472.

18 A. A. Kadi, H. W. Darwish, M. W. Attwa and S. M. Amer, PLoS One, 2016, 11, e0164967.

19 H. W. Darwish, A. A. Kadi, M. W. Attwa and H. S. Almutairi, Clin. Chim. Acta, 2018, 480, 180-185.

20 M. W. Attwa, A. A. Kadi, H. W. Darwish, S. M. Amer and H. Alrabiah, Eur. J. Mass Spectrom., 2018, 24, 344-351. 
21 S. M. Amer, A. A. Kadi, H. W. Darwish and M. W. Attwa, Chem. Cent. J., 2017, 11, 45.

22 A. A. Kadi, A. S. Abdelhameed, H. W. Darwish, M. W. Attwa and N. S. Al-Shakliah, Biomed. Chromatogr., 2016, 30, 1248-1255.

23 A. S. Abdelhameed, M. W. Attwa and A. A. Kadi, Biomed. Chromatogr., 2017, 31, e3793.

24 Food and Drug Administration, Guidance for Industry, FDA Bioanalytical Method Validation. US Department of Health and Human Services, May 2018.

25 N. Kadian, K. S. R. Raju, M. Rashid, M. Y. Malik, I. Taneja and M. Wahajuddin, J. Pharm. Biomed. Anal., 2016, 126, 83-97.
26 G. Caldwell and Z. Yan, Optimization in drug discovery: in vitro methods, Springer Science \& Business Media, 2014.

27 A. Manzo, A. Montanino, R. Costanzo, C. Sandomenico, G. Palumbo, C. Schettino, G. Daniele, A. Morabito, F. Perrone and M. C. Piccirillo, in Oncogenomics, ed. F. Dammacco and F. Silvestris, Academic Press, 2019, pp. 477-486, DOI: 10.1016/B978-0-12-811785-9.00033-8.

28 M. W. Attwa, A. A. Kadi, H. W. Darwish and A. S. Abdelhameed, RSC Adv., 2018, 8, 40387-40394.

29 M. W. Attwa, H. W. Darwish, H. A. Alhazmi and A. A. Kadi, Clin. Chim. Acta, 2018, 485, 298-304.

30 H. W. Darwish, M. W. Attwa and A. A. Kadi, Trop. J. Pharm. Res., 2016, 15, 2467-2473. 